\title{
Plant-derived acetylcholinesterase inhibitory alkaloids for the treatment of Alzheimer's disease
}

\author{
This article was published in the following Dove Press journal: \\ Botanics:Targets and Therapy \\ 10 January 2013 \\ Number of times this article has been viewed
}

\section{Stefano Dall'Acqua \\ Department of Pharmaceutical and Pharmacological Sciences, University of Padova, Padova, Italy}

\begin{abstract}
The inhibition of acetylcholinesterase (AChE) has been one of the most used strategies for the treatment of Alzheimer's disease (AD). The AChE inhibitors (AChE-I) produce not only short-term symptomatic effects, but can also play a role in other pathological mechanisms of the disease (eg, formation of amyloid- $\beta$ plaques), which has renewed interest in the discovery of such inhibitors. Four of the five currently prescribed treatments for AD are AChE-I. Natural alkaloids such as galantamine or alkaloid-related synthetic compounds (such as rivastigmine) are considered beneficial for patients with mild-to-moderate AD. However, there is a need for the discovery of more effective compounds and for this reason, plants can still be a potential source of new AChE-I. Findings and advances in knowledge about natural alkaloids as potential new drugs acting as AChE-I will be summarized in this paper.
\end{abstract}

Keywords: quinolizidine, steroidal, indole, isoquinoline

\section{Introduction}

Alzheimer's disease (AD), an irreversible neurodegenerative disorder primarily targeting elderly populations, affects approximately 36 million people worldwide according to the 2010 estimations. ${ }^{1-5}$ This illness is characterized by progressive neurodegenerative disorders, collapse of cognitive functions, and formations of amyloid plaques and neurofibrillary tangles. ${ }^{2,3} \mathrm{AD}$ is the most frequent cause of dementia in mid- to late life, and has a devastating impact on public health and society.

The AD pathogenesis is complex and comprises genetic and environmental factors, ${ }^{4-7}$ thus AD is considered a multifactorial disease. Different hypotheses regarding the pathological routes of AD have been proposed and the two main hypotheses are related to the cholinergic, amyloid- $\beta(\mathrm{A} \beta)$, and tau proteins. For this reason, drugs acting on acetylcholine (ACh) levels, mainly acetylcholinesterase inhibitors (AChE-I), or that reduce the formation of toxic $A \beta$ peptides, mainly noncompetitive $\beta$-secretase (BACE-1) and secretase inhibitors, were studied for the development of anti-AD drugs. ${ }^{2}$ By its pharmacological nature, cholinesterase inhibitory therapy may be considered as a simple symptomatic intervention. However, therapy with AChE-I can be effective over a longer period, ${ }^{8}$ and it is believed that AChE also plays an important role in $\mathrm{A} \beta$ deposition. ${ }^{8-10}$ It seems likely that $\mathrm{AChE}$ interacts with $\mathrm{A} \beta$ and promotes the formation of amyloid fibril through a pool of amino acids located in proximity to the peripheral anionic-binding site of the enzyme. ${ }^{9}$ Furthermore cholinergic neurons are subject to control via the modulation of nicotinic ACh receptors (nAChRs) and some AChE inhibitors, such as galantamine, bind at allosteric secondary binding sites, and potentiate the receptor response to the available ACh. ${ }^{11}$ Since AD is a multifactorial
Correspondence: Stefano Dall'Acqua Department of Pharmaceutical and Pharmacological Sciences, University of Padova, Via Marzolo 5 35I00, Padova, Italy

Email stefano.dallacqua@unipd.it 
disease, the recent trend in the search for new drugs also focuses on multitargeted compounds.

Many plant-derived alkaloids that act as AChE-I can be considered as models for the development of AD drugs, and for example galantamine ${ }^{11-13}$ and rivastigmine ${ }^{14}$ are available for the symptomatic treatment of patients with mild to moderate AD. Three ChE-Is are the most frequently used drugs to treat patients with mild to moderate AD: donepezil, rivastigmine, and galantamine. Donepezil and galantamine are selective AChE-Is. Rivastigmine inhibits both AChE and butyrylcholinesterase (BuChE) from degrading $\mathrm{ACh}$. The usefulness of donepezil, rivastigmine, and galantamine in the treatment of patients with AD has been recognized in recent health technology assessments. ${ }^{15}$ However, there is still a need for new AChE-I lead compounds with lower toxicity and higher central nervous system (CNS) penetration. Many plants have been studied by bioassay-guided approaches for the identification of new AChE-Is ${ }^{16}$ and different classes of plant-derived natural products have been considered as new AChE-Is potentially useful for AD treatment. ${ }^{17}$ Both nonalkaloids and alkaloid-derivative compounds ${ }^{16}$ have been studied, but the most potent AChE-I nowadays appear to be natural or semisynthetic alkaloids. This review focuses on plant-derived alkaloids with AChE-I properties and their potential role as models for the development of drugs for AD treatment.

\section{Acetylcholinesterase inhibitors as anti-Alzheimer drugs}

The AChE present in the CNS catalyzes the hydrolysis of the ACh to choline. ACh is released in the synaptic cleft, where it activates both postsynaptic and presynaptic cholinergic receptors, namely nicotinic and muscarinic, leading to an increase of cholinergic transmission, which results in cognition improvement. ${ }^{18}$ Its neural-stimulating activity is terminated by the action of the cholinesterase enzymes, namely $\mathrm{AChE}$ and BuChE. In AD patients, a deficit of this neurotransmitter was observed and this led to the so-called cholinergic hypothesis. ${ }^{4}$

Classified as a serine hydrolase, the enzyme AChE uses three amino acidic residues in the active site: histidine, serine, and glutamic acid. The first two activate the side chain of a serine residue. Once the active site serine forms a tetrahedral intermediate with the Ach carbonyl group, choline is released. Then a water molecule is employed in the active site for releasing acetate from the serine, which returns the enzyme back to its original state. The enzyme active site is located at the bottom of a $20 \AA$ gorge acting as a bottleneck in which some aromatic residues line up the entry and contribute to its specificity of action. ${ }^{2}$ The enzyme AChE is the target of the available AChE-Is for AD treatment and the aim is obviously to restore, at least in part, the levels of the neurotransmitter (Figure 1). This approach can be considered

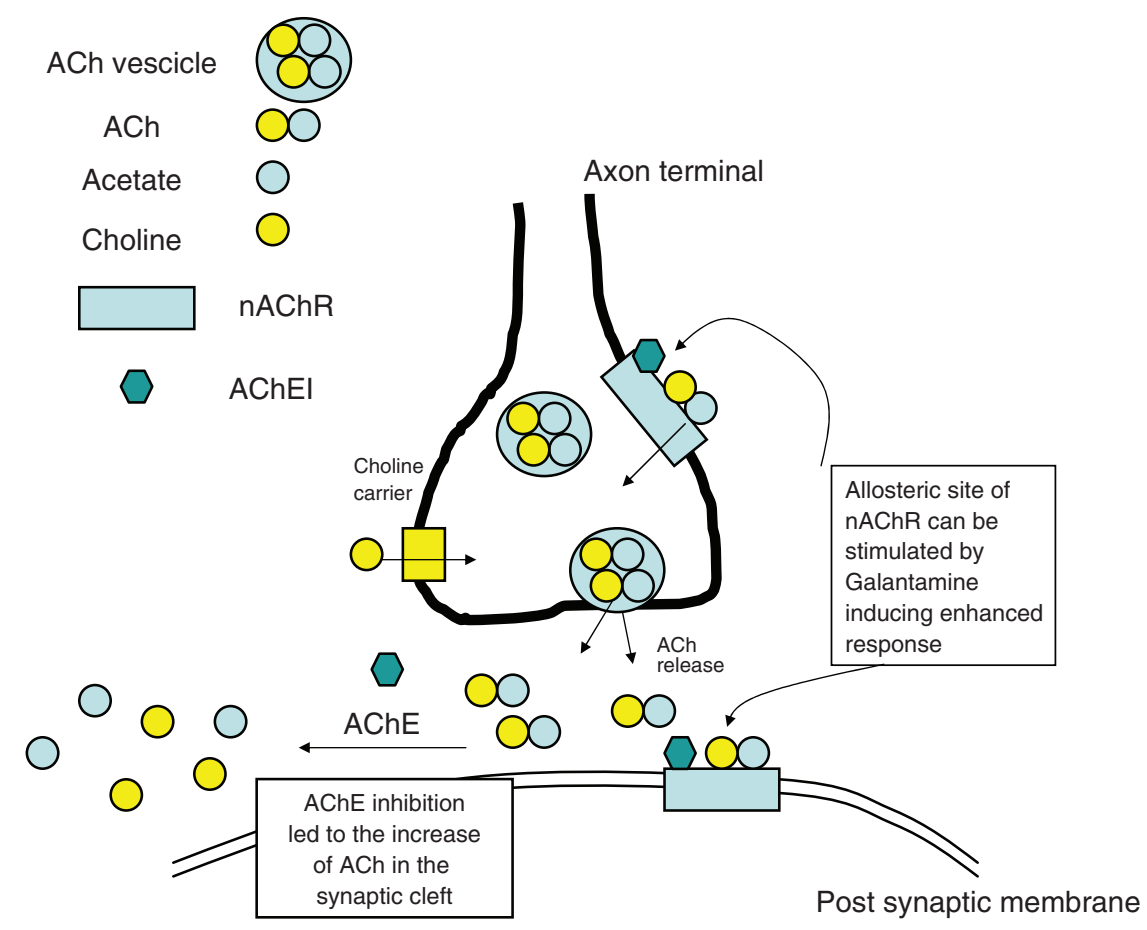

Figure I Schematic representation of the mode of action of AChl, acting as enzyme inhibitors or, as galantamine, stimulating nAChR. 
as a symptomatic short-term intervention, but some data emerging from long-term open-label trials have shown that the effect may be prolonged. For this reason, the observed effect of stabilization of the cognitive status of patients suggests the presence of further mechanisms. ${ }^{16}$ Cholinesterase inhibitors could perhaps help the prevention of the formation of $\beta$-amyloid plaques, while the peripheral site of AChE promotes aggregation of $\beta$-amyloid peptides. ${ }^{19}$ Other mechanisms are also under investigation and multitargeted drugs will be preferred due to the multifactorial pathogenesis of the disease. The use of AChE-I has been associated with an anti-inflammatory effect mediated by $\alpha-7$ nAChRs. The inflammatory component in $\mathrm{AD}$ is very important and the role of inflammation and AChE-I emphasizes the role of cholinergic balance in this pathology.

\section{Alkaloids as acetylcholinesterase inhibitors}

On one hand, many natural alkaloids have been studied as AChE-Is, but relatively few compounds have entered therapeutic use. On the other hand, many different classes of compounds have been considered, namely indole derivatives (such as physostigmine and related compounds), isoquinoline and related derivatives (such as galantamine and lycorinetype alkaloids), steroid and terpenoid alkaloids, and many other derivatives that present significant inhibitory effects on AChE. ${ }^{16}$ Plant families that have been considered as potential sources of such alkaloids were Amaryllidaceae, Buxaceae, Apocynaceae, Papaveraceae, Lycopodiaceae, and Leguminosae. The great chemical diversity of the different derivatives studied presents the opportunity to explore various chemical scaffolds for the development of potential new drugs to act on enzymes with different pharmacological profiles. One opportunity is to generate new AChE-Is coupled with properly selected bioactive molecules to obtain homo- and heterodimers endowed with increased potency and supplementary actions. ${ }^{20}$ Furthermore, compounds possessing not only the AChE inhibitory properties, but also other antiinflammatory or antioxidant qualities, such as protoberberine and related compounds are considered attractive because of the possibility to create multitargeted drugs acting with different mechanisms all related to the disease.

\section{Indole alkaloids and related compounds}

The indole alkaloid family is probably the most important source of active natural products in compounds that have entered clinical use. Indole alkaloids are found in a large group of plants and also in fungi. Reserpine, yohimbine, vincamine, and vinblastine are only some examples of such compounds with medicinal importance. The majority of these alkaloids are derived from tryptophan and the monoterpenoid secologanin, yielding complex formations of tetracyclic (as agroclavine), pentacyclic (ajmalicine) hexacyclic (apodine), and heptacyclic (brucine) structures. ${ }^{21}$ Physostigmine (Figure 1) is the main alkaloid of the Calabar bean, the seed of Physostigma venenosum (Leguminosae), and was one of the first investigated AChE-Is. This compound acts as a parasympathomimetic agent and is able to pass through the blood-brain barrier. It is a potent short-acting inhibitor of the enzyme and has been shown to improve the cognitive function in vivo and both in normal and AD patients. ${ }^{13-16,22,23}$ Rivastigmine is considered a "pseudoirreversible" inhibitor of AChEs and BuChEs with a phenylcarbamate structure, the metabolism of which is almost totally independent of the hepatic cytochrome P450 system. After binding to cholinesterase, the carbamate portion of rivastigmine is slowly hydrolyzed, cleaved, conjugated to a sulfate, and excreted. Rivastigmine has an oral bioavailability of 0.355 and low $(40 \%)$ binding to plasma proteins. Its elimination half-life is around 2 hours. ${ }^{14}$ Its short half-life, narrow therapeutic index, and secondary effects did not allow its clinical use. ${ }^{16,22,23}$ However, the indole alkaloids family still remain an important source of new AChE-Is. 4,17,23

Therefore, starting with physostigmine, many derivatives were prepared to improve efficacy and the pharmacokinetic profile. Phenserine, tolserine, and several derivatives (Figure 1) present potent AChE-I activity with an halfmaximal inhibitory concentration $\left(\mathrm{IC}_{50}\right)$ in the nanomolar range. ${ }^{4,17}$ The synthetic modification occurred in the substituent pattern of the phenyl group of the phenylcarbamoyl moiety of the phenserine compound. Simple aliphatic chains (as methyl-, di-, or trimethyl groups) were linked in each position of the aromatic ring leading to a series of derivatives with similar AChE-I properties to the starting compound. As our first example, the phenylcarbamate derivative phenserine was proposed as a new potent inhibitor. The compound was considered less toxic and more active compared with physostigmine, and in vivo studies reported its efficacy in cognition enhancement and $\beta$-amyloid peptide formation. ${ }^{17}$ In particular, the compound is able to act as an AChE-I and to inhibit amyloid precursor protein gene. ${ }^{4,24}$ Furthermore the $(-)$ phenserine enhanced cognition in vivo and in AD patients (at a dose of $30 \mathrm{mg} /$ day), but in Phase III clinical studies, there was no difference in effects compared to placebo in $\mathrm{AD}$ patients. Also the dextrorotatory enantiomer $(+)$ phenserine 
was considered and it was used in a Phase I clinical study, but further clinical studies are not planned. ${ }^{4,25}$

Recently, a shrub that was used in folk medicine for the treatment of various diseases, Himatanthus lancifolius, was studied for the possible anti-AChE properties of its alkaloids. The plant contains several indole alkaloids. Rich fractions of lipophilic alkaloids were able to act as AChE-I and uleine (Figure 1) was isolated from them. ${ }^{22,26}$ This alkaloid was firstly isolated from the root bark of Aspidosperma ulei Mgf and was studied from a chemical and synthetic point of view. ${ }^{27-30}$ Furthermore, this alkaloid and its related derivatives were also studied for their anticancer properties, ${ }^{30}$ and, more recently, alkaloids-enriched fractions were also studied for their in vitro anti-inflammatory properties. ${ }^{31}$ It was reported recently that uleine has significant AChE-I activity with an $\mathrm{IC}_{50}$ of $0.45 \mu \mathrm{M} .{ }^{26}$ For this reason, uleine is considered as a new possible candidate for the future development of new anti-AD drugs, but no reports about safety, efficacy, and human studies specific to cognition have been reported to date. ${ }^{22,26}$

\section{Isoquinoline and Amaryllidaceae alkaloids}

Isoquinoline alkaloids are probably the largest single group of plant alkaloids. ${ }^{21}$ Their basic structure is derived from tetrahydroisoquinoline, which can be modified in complex structures that can be all biosynthetically derived from phenylalanine and tyrosine. These alkaloids are aromatic bases; the majority of the natural derivatives present tetracyclic structures, but pentacyclic compounds (such as aporphine and emetines) are also present. The most widely distributed isoquinoline alkaloids are the aporphines and protoberberine types. ${ }^{21}$ The morphine-correlated compounds are the most notable for their medicinal chemistry and clinical use in this important class of compounds. The presence of Amaryllidaceae alkaloids, as their name suggests, is restricted to the Amaryllidaceae family and no other classes of alkaloids were reported from this source. The daffodil family includes narcissus, snowdrops, and amaryllis and is formed by 75 genera and about 1100 species. ${ }^{21}$ All these alkaloids share a C-15 skeleton and their biosynthesis involves the phenolic coupling of two aromatic amino acids with one of the two nitrogen atoms retained in the process. ${ }^{21}$ These two classes of alkaloids are considered very important AChE-Is.

The alkaloid galantamine is one of the most important derivatives with great therapeutic value for $\mathrm{AD}$ treatment (Figure 2). This compound was isolated from Galanthus
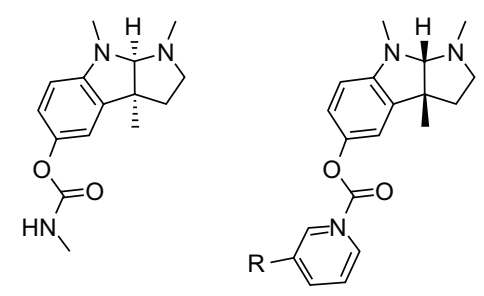

Physostigmine

$$
\mathrm{R}=\mathrm{H} \text { phenserine }
$$$$
\mathrm{R}=\mathrm{CH}_{3} \text { tolserine }
$$

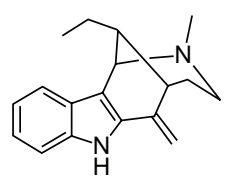

Uleine

Figure 2 Structures of some active antiacetylcholinesterase indole alkaloids.

woronowii and G. nivalis and some Narcissus and Leucojum spp. of Amaryllidaceae. This compound is reported to be more selective to $\mathrm{AChE}$ than $\mathrm{BuChE}$ and provides good oral bioavailability (between $80 \%$ to $100 \%$ ) with linear pharmacokinetics. ${ }^{16,22}$ Galantamine inhibits the breakdown of ACh by binding competitively and reversibly to the active site on AChE. Of particular importance are the inhibitory effects of galantamine on $\mathrm{AChE}$ in the frontal cortex and hippocampal regions of the brain, the two areas in which cholinergic neurotransmission is most affected in patients with $\mathrm{AD} .{ }^{11} \mathrm{In}$ addition galantamine has a peculiar mechanism of action because it both acts as competitive inhibitor of the enzyme and as a positive allosteric modulator of nAChRs. ${ }^{11,22}$ The inhibition of $\mathrm{AChE}$ is potent and selective (53-fold greater compared to $\mathrm{BuChE})^{11}$ and the effect is observed in the frontal cortex and hippocampal region of the brain, which are areas that present poor cholinergic neurotransmission in the $\mathrm{AD}$ patients. The relatively low affinity for BuChE, mainly diffused in plasma, is considered an advantage in terms of the poor peripheral effect of the drug. ${ }^{11}$ The second mechanism of action of galantamine is the allosteric modulation of nAChRs. Galantamine binds to a secondary (allosteric) site in the $\mathrm{nAChR}$, and this makes the receptor more sensitive to the physiologic ligand (ACh), which enhances the response to the available ACh. Furthermore, in vivo studies in animal models suggest that the modulatory activity of galantamine in nAChRs increases the number of such receptors in longterm treatments. ${ }^{11,32}$ Galantamine is actually used in therapy (as Reminy $1^{\circledR}($ Janssen-Cilag SpA,)) and its use is associated

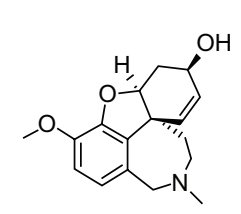

Galantamine

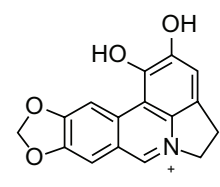

Ungeremine

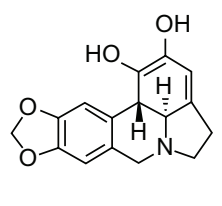

Lycorine
Figure 3 Structures of selected isoquinoline and Amaryllidaceae alkaloids active as acetylcholinesterase inhibitors. 

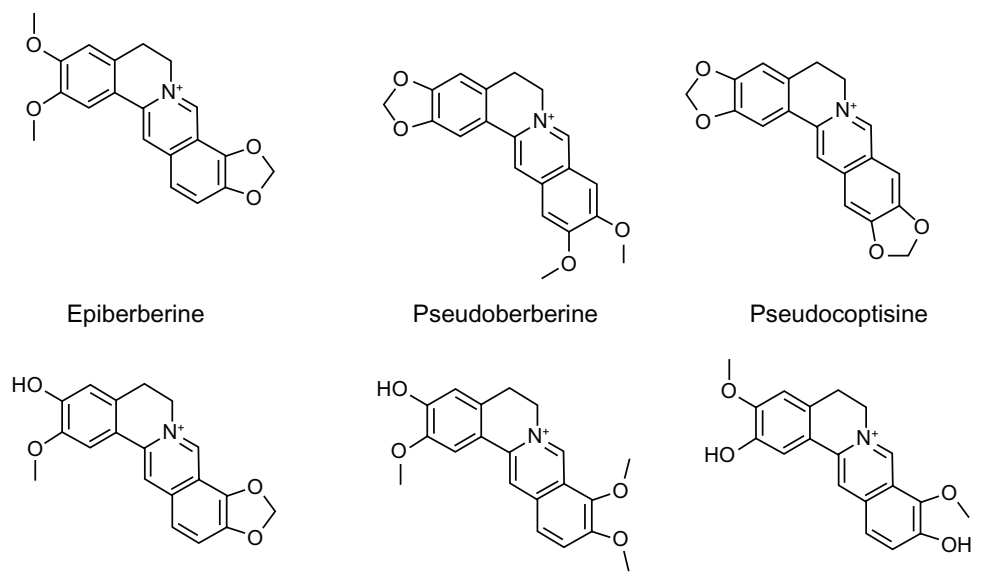

Groenlandicine

Jatrorrhizine

Stepharanine

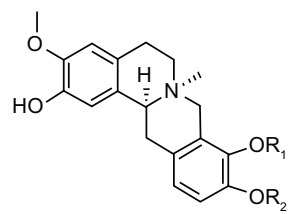

$\mathrm{R}_{1}=\mathrm{HR}_{2}=\mathrm{CH}_{3}$ cyclanoline

$\mathrm{R}_{1}=\mathrm{CH}_{3} \mathrm{R}_{2}=\mathrm{HN}$-methyl stepholidine

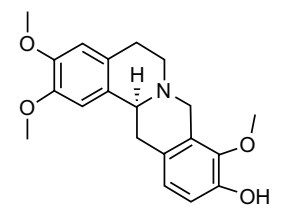

Cordylamine

Figure 4 Structures of protoberberine-related alkaloids.

with a preservation of cognitive function in patients with AD. It also stabilizes patients and postpones the emergence of behavioral symptoms, which improves aberrant motor behavior, anxiety, disinhibition, and hallucinations. ${ }^{1,11}$ Of the various natural products that have been studied, galantamine is considered a well-tolerated treatment for the control of AD progression. ${ }^{11}$

Several derivatives were prepared from the galantamine scaffold including $\mathrm{C}$ and $\mathrm{D}$ ring modifications, quaternary ammonium salts, carbamate and esters, and bis-interacting ligands, but pharmacology studies on the possible efficacy of these compounds are still lacking. ${ }^{17}$

Ungeremine and lycorine (Figure 2) were isolated from Nerine bowdenii W Watson (Amaryllidaceae) and from Narcissus pseudonarcissis (Amaryllidaceae). These compounds are moderate AChE-Is, and have been used as models for the preparation of several synthetic derivatives with the aim of improving the AChE-I activity of the starting compounds. ${ }^{17}$ Considering the different Amaryllidaceae alkaloids, the lycorine type derivatives exhibited the higher activity, namely $\mathrm{O}$-acetyl lycorine was twofold more potent than galantamine. ${ }^{17}$

New therapeutic treatments should target multiple AD pathways to prevent the rapid progression of $\mathrm{AD}$ as opposed to the traditional "one drug, one target" approach, and for this reason some isoquinoline and benzylisoquinoline derivatives were considered potentially useful compounds. Alkaloids from Colchicum speciosum Steven (Colchicaceae), Coptis spp. (Ranunculaceae) and Corydalis spp. (Papaveraceae) act as AChE-Is. ${ }^{12}$ Epiberberine, pseudoberberine, and pseudocoptisine are examples of such compounds. Berberin was recently considered as an attractive compound for $\mathrm{AD}$ treatment not only due to its AChE-I, but also for BuChE, antioxidant, monoamine oxidase inhibitory, amyloid- $\beta$ peptide level-reducing and cholesterol-lowering activities which suggest a multitargeted approach for the disease's treatment. ${ }^{33}$ Berberin-based derivatives were developed to prepare more potent AChE-Is. ${ }^{34}$ Pseudoberberine and pseudocoptisine are also able to alleviate scopolamine-induced memory impairment in vivo models. ${ }^{35,36}$ Structures of some derivatives that have been studied for their AChE-I properties are reported in Figure 3.

With an interesting mechanism of action, some C. chinensis alkaloids with AChE-I properties also

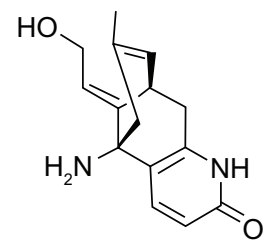

Carinatumin A

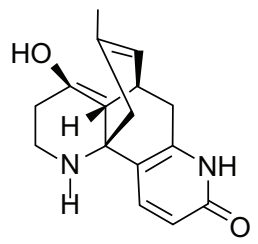

Carinatumin B

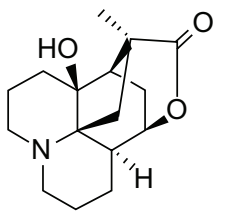

Annotine 


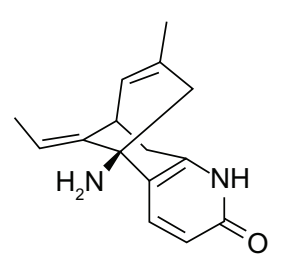

Huperzine A

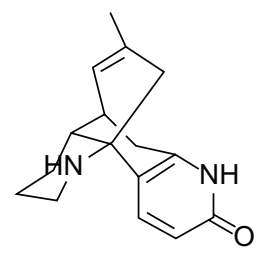

Huperzine B

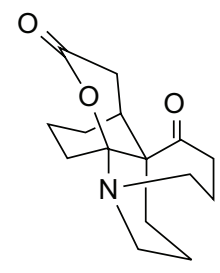

Lycojapodine
Figure 6 Structures of Huperzine and Lycojapodine alkaloids.

displayed BACE-1 inhibitory activity. These compounds are groenlandicine and jatrorrhizine and their derivatives. These alkaloids also present antioxidant activity, therefore they possess multiple activities relevant to AD. ${ }^{37}$

Alkaloids from Stephania venosa Spreng. (Menispermaceae) such as stepharanine, cyclanoline, and N-methyl stepholidine are potent AChE-Is. The structural activity relationships of this protoberberine derivative revealed that a positive charge at the nitrogen of the tetrahydroisoquinoline portion, a steric substitution at the same nitrogen, and a planarity of the compound are important features for AChE-I. Pattern substitution at positions 2, 3, 9 and 10 can also modulate activity and the $S$. venosa derivatives stepharanine and cyclanoline were more potent than cordylamine. ${ }^{38}$

\section{Quinolizidine and Lycopodium alkaloids}

The quinolizidine alkaloids possess a structural unit in which a nitrogen atom occupies a central position in two six-member fused rings. In general, such alkaloids are found in Leguminosae and mainly in plants of the genus Lupinus. A typical bicyclic structure is found in lupin and in other more complex structures such as anagyrine, which possess more cycles. These compounds are quite toxic and their occurrence in trees and shrubs is the cause of accidental poisoning in sheep and in some cases also in humans. Some of these alkaloids have been studied for their potential medicinal use. Lycopodium alkaloids are related to quinolizidine, but possess an unusual tetracyclic ring system. Several derivatives have been reported, which differ in their ring closures and rearrangements as well as for methylhydroxyl or other substituent positions. As a class, the Lycopodium alkaloid compounds are moderately toxic. ${ }^{21}$

The carinatumins A and B (from Lycopodium carinatum Desv. ex Poir.), and other alkaloids isolated from Lycopodium spp. present interesting AChE-I activity. Their structures are reported in Figure 4. For example, carinatumins A and B present an $\mathrm{IC}_{50}$ of 4.6 and $7.0 \mu \mathrm{M}$, respectively. ${ }^{4,39}$ Carinatumins $\mathrm{A}$ and $\mathrm{B}$, lycoparin $\mathrm{C}$, and other derivatives present significant AChE-I activity, but none of these alkaloids are considered of therapeutic relevance to date. Lycojapodine A is an unusual $\mathrm{C} 16 \mathrm{~N}$ type alkaloid isolated from L. japonicum that possesses a 6/6/6/7 tetracyclic ring system. ${ }^{4}$ Its AChE-I activity is similar to galantamine and it could be a future potential new candidate for the development of AD drugs. Annotine from $L$. annotinum and other lycoparin $\mathrm{C}$ derivatives from $L$. casuarinoides (Spring) were studied for their AChE-I properties, but data about efficacy or safety for possible clinical use are lacking. ${ }^{40,41}$

A new Lycopodium alkaloid with a peculiar structure was isolated from the traditional Chinese medicine qing ceng ta, namely the Huperzia serrata, Huperzine A (Hup A; Figure 5). This compound is considered a new potential drug for the treatment of AD patients. This alkaloid is a potent, reversible AChE-I, whose activity is comparable to the other well-known alkaloids, physostigmine, galantamine, or tacrine. In the 1990s, this alkaloid was approved in China as an anti-AD drug and is currently marketed and patented in the USA as a dietary supplement. ${ }^{42-44}$ Compared to physostigmine or galantamine, Hup A presents higher selectivity to $\mathrm{AChE}$ versus BuChE. After oral or intraperitoneal administration, Hup A produced significant inhibition of AChE in the cortex, hippocampus, corpus striatus, medial septum, medulla oblongata, cerebellum, and hypothalamus in rats. Furthermore, studies in animal models revealed

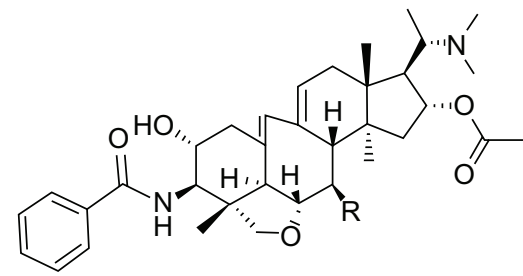

$\mathrm{R}=\mathrm{OH} \mathrm{O}^{6}$-buxafurandiene

$\mathrm{R}=\mathrm{H}$ 7-deoxy-O6 ${ }^{6}$-buxafurandiene

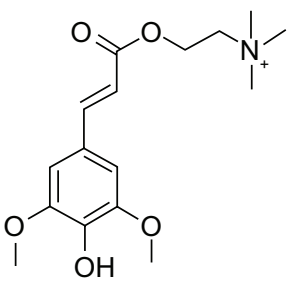

Sinapine<smiles>COc1ccc2c(=O)oc3ccc(CCN(C)C)c4c(=O)oc1c2c34</smiles>

Tapsine

Figure 7 Examples of structures of miscellaneous alkaloids. 
that, compared to donepezil and tacrine, Hup A has higher bioavailability and more easily penetrates the blood-brain barrier., ${ }^{42-44}$ Hup A acts as a mixed competitive inhibitor and some findings can elucidate in part how this alkaloid can bind to the enzyme. The principal interactions include a direct hydrogen bond between the carbonyl group and the hydroxyl oxygen of Tyr 130 at a peripheral site of the enzyme. A further interaction is between the ethylidene methyl group and the main chain oxygen of His 440 . Another interaction is the indirect hydrogen bond mediated by water molecules with the aminoacidic residues that constitute the active centre of the enzymes, and the cation interactions induced upon inhibitor binding, between the aminogroup of the alkaloid and the aromatig of Trp 84 and Phe 330 at the choline site. This binding site is shared with other AChE-Is such as tacrine and edrophonium. ${ }^{45}$ The high selectivity of this alkaloid was also studied with the aid of computerassisted docking studies and with the crystal structure of the AChE-Hup A complex. For example, Hup A is able to form an hydrogen bond with the residue of Tyr 337 within a choline site that exists only in the mammalian homolog of the enzyme, but is not present in the torpedo enzyme and also in BuChE. ${ }^{44,46}$ The alkaloid Hup A is considered a promising compound due to other mechanisms of action that have been studied recently, namely the reduction of the aggregation and deposition of $A \beta$, the regulation of the
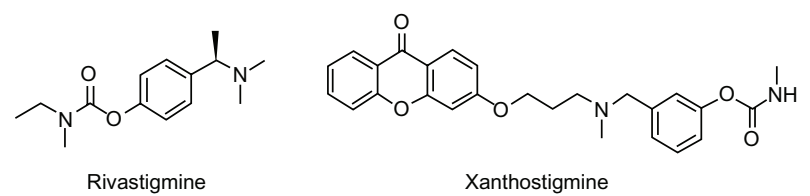

Figure 8 Structures of rivastigmine and xanthostigmine.

$\beta$-amyloid precursor protein metabolism, and the decrease of $A \beta$-associated neurotoxicity. ${ }^{47,48}$

Some clinical studies have reported significant improvements in memory deficiencies in aged patients and AD patients. A recent meta-analysis of Hup A's efficacy and safety showed it is well tolerated and significantly improves cognitive performance and activities of patients with $\mathrm{AD}$. The closely related Hup B is a less potent AChE-I, and probably for this reason it has not been extensively investigated for its possible clinical uses.

\section{Triterpenoid steroidal alkaloids}

The triterpenoid skeleton appears to be a potential scaffold for the development of AChE-I. Some reports describe the AChE-I of nonalkaloidal triterpenoids. ${ }^{16}$ However, nitrogencontaining compounds such as hyrcanone, hyrcamine, or buxidine (isolated from Buxus spp.) were described as moderate inhibitors of the enzyme AChE. A number of steroidal alkaloids were isolated from Buxus, Sarcococca, and Fritillaria spp. and, for example, (+)-O ${ }^{6}$-buxafurandiene

Table I Alkaloids with AChE-I activity with a potential use in AD disease

\begin{tabular}{|c|c|c|c|c|}
\hline Alkaloid class & Structure & Main compound & Plant family & Notes \\
\hline Indole & & Physostigmine & Leguminosae & $\begin{array}{l}\text { Physostigmine is not clinically } \\
\text { used anymore. }\end{array}$ \\
\hline \multirow[t]{2}{*}{ Isoquinoline } & & Galantamine & Amaryllidaceae & $\begin{array}{l}\text { Galantamine acts as both AChE-I and } \\
n A C h R \text { and is currently in clinical use. }\end{array}$ \\
\hline & & $\begin{array}{l}\text { Groenlandicine, } \\
\text { jatrorrhizine }\end{array}$ & Ranunculaceae & $\begin{array}{l}\text { These compounds, which act as } \\
\text { AchE-I and noncompetitive } \beta \text {-secretase } \\
\text { I inhibitors, also possess antioxidant } \\
\text { activity. }\end{array}$ \\
\hline Lycopodium type & & Huperzine A & Huperziaceae & $\begin{array}{l}\text { AChE-I activity, reduction of } A-\beta \\
\text { deposition, decreases } A-\beta \text { related } \\
\text { neurotoxicity. }\end{array}$ \\
\hline
\end{tabular}


and (+)-7-deoxy-O ${ }^{6}$-buxafurandiene (Figure 6) presented significant AChE-I activity. Several different papers have been published about this compound and the structural activity relationships are described at least in part. ${ }^{12,49-51}$ In many derivatives that have been isolated, the activity may be associated with the presence of an $\alpha, \beta$-unsaturated amide at $\mathrm{C}-3$ of the ring $\mathrm{A}$, and with the presence of a $\alpha, \beta$-unsaturated carbonyl moiety. ${ }^{4,42,49}$ Furthermore, the presence of the dimethylamino moiety at C-20 and the basic nitrogen atom can enhance the structural activity and also improve the active transport of the compounds in the cell. Such compounds are studied as new candidates for the development of new AD drugs, but reports about their in vivo or clinical studies are still lacking. ${ }^{4}$

\section{Miscellaneous alkaloids}

Ribalinine and methyl isoplatydesmine were isolated from Skimmia laureola (Rutaceae) and present significant AChE-I activity. Quinoline (nigellastrine), and $\beta$-carboline (harmine and related products), tetrahydroisoquinoline (salsoline and derivatives) from Salsola spp. (Chenopodiaceae) present significant AChE-I activity.,52 Nevertheless, pharmacological studies about efficacy and safety are still lacking. Compared to other alkaloid classes, the piperidines are less studied as AChE-Is. (-)-spectaline and derivatives isolated from Cassia spectabilis are an example of this and the compounds were used to develop the synthetic derivative. Other alkaloids that are considered of therapeutic interest are sinapine that is an ester of sinapinic acid and choline that is present is Raphanus sativus, which acts as a powerful AChE-I in vitro, and tapsin isolated from Magnolia $x$ solangiana Soul.-Bod (Magnoliaceae), which presents an AChE-I activity greater than galantamine $\left(\mathrm{IC}_{50}=0.3 \mu \mathrm{M}\right.$ vs $3.2 \mu \mathrm{M}$, respectively). ${ }^{4,53}$

As observed previously, many natural derived alkaloids have been studied as an AChE-I with potential use in $\mathrm{AD}$, but they also have been used as models to synthesize new compounds. One example is rivastigmine (Figure 7), which is a simple synthetic derivative approved as treatment for moderate-to-mild AD in the USA in 2000, with doses of 6-12 $\mathrm{mg}$ /day resulting in improvement of cognition in patients. ${ }^{22,54}$ Recently the drug was also proposed in the form of a transdermal patch to reduce the side effects that are mainly nausea, vomiting, anorexia, and diarrhea. ${ }^{22}$ The derivative, xantostigmine (Figure 7) is able to inhibit AChE-induced $\beta$-amyloid aggregation. ${ }^{55}$

\section{Conclusion}

$\mathrm{AD}$ is the most frequent form of dementia and is characterized by memory loss, mental and physical behavioral changes, and reduced quality of life for patients, with an important impact on public health. The pathology is progressive and causes $\beta$-amyloid plaque formation and deficiency in the neurotransmitter acetylcholine in the brain. Nowadays the available drugs have limited effect on this pathology, and in fact are only able to control symptoms to preserve cognitive function and slow down the progression of the illness. AD is a multifactorial disease and several pathogenic events are involved in this disease including primary events such as genetics, neuronal death, brain dysfunction. Furthermore, secondary ( $\beta$-amyloid deposition, tau protein hyperphosphorylation), tertiary (neurotransmission deficiency, neuroinflammation), and quaternary (neuronal death, free radical formation, cerebrovascular dysfunction) events also play a complex role in this pathology. Despite the new findings, AChE-I still represents an important symptomatic therapy and research of new drugs acting on this enzyme is essential. The plant kingdom, an important source of several drugs or "lead compounds" for medicinal chemistry, is still largely unexplored despite the relatively large amount of tested plant extracts for anti-AChE-I. In recent years, many botanical species have been studied as potential sources of AChE-I alkaloids, but relatively few isolated compounds were considered as potential new "leads" for the development of drugs for AD treatment (Table 1). Different compounds belonging to various alkaloids classes were identified as enzyme inhibitors, in some cases not only from plants, but also from other natural organisms. ${ }^{12,16,56}$ These findings produce an opportunity to modify and prepare several useful derivatives by synthesis or semisynthesis to understand their structural activity relationships. Many of the studied alkaloids have been studied by in vitro or in some cases in vivo models, but future studies are needed to demonstrate their therapeutic role. No human or animal studies have been performed in many compounds, therefore studies of their safety, efficacy, and toxicity are needed. Many approved drugs in the market for AD treatment are natural alkaloids and galantamine is an example. Furthermore, many AChE-I compounds studied as potentially relevant agents in AD treatment are primarily from plants. The evidence that AD is a multifactorial disease is also guiding the research in the direction of multiple targeted compounds. In this case, many natural alkaloids (such as protoberberine and related compounds) have been studied not only for their AChE-I properties, but also for their 
anti-inflammatory and antioxidant activities that can play an important role in the development of new anti-AD drugs.

\section{Disclosure}

The author reports no conflicts of interest in this work.

\section{References}

1. Prince M, Bryce R, Ferri C. World Alzheimer Report 2011. London, UK: Alzheimer's Disease International (ADI); 2012.

2. Mohamed T, Rao PPN. Alzheimer's disease: Emerging trends in small molecule therapies. Curr Med Chem. 2011;18(28):4299-4320.

3. Suh WH, Suslick KS, Suh YH. Therapeutic agents for Alzheimer's disease. Curr Med Chem Cent Nerv Syst Agents. 2005;5(4):259-269.

4. Williams P, Sorribas A, Howes MJ. Natural products as a source of Alzheimer's drug leads. Nat Prod Rep. 2011;28(1):48-77.

5. Citron M. Alzheimer's disease: treatments in discovery and development. Nat Neurosci. 2002;5(Suppl):1055-1057.

6. Citron M, Oltersdorf T, Haass C, et al. Mutation of the $\beta$-amyloid precursor protein in familial Alzheimer's disease increases $\beta$-protein production. Nature. 1992;360(6405):672-674.

7. Scheuner D, Eckman C, Jensen M, et al. Secreted amyloid $\beta$-protein similar to that in the senile plaques of Alzheimer's disease is increased in vivo by the presenilin 1 and 2 and APP mutations linked to familial Alzheimer's disease. Nat Med. 1996;2(8):864-870.

8. Bullock R, Dengiz A. Cognitive performance in patients with Alzheimer's disease receiving cholinesterase inhibitors for up to 5 years. Int J Clin Pract. 2005;59(7):817-822.

9. De Ferrari GV, Canales MA, Shin I, Weiner LM, Silman I, Inestrosa NC. A structural motif of acetylcholinesterase that promotes amyloid $\beta$-peptide fibril formation. Biochemistry. 2001;40(35):10447-10457.

10. Hardy J, Selkoe DJ. The amyloid hypothesis of Alzheimer's disease: Progress and problems on the road to therapeutics. Science. 2002;297(5580):353-356.

11. Lilienfeld S. Galantamine-A novel cholinergic drug with a unique dual mode of action for the treatment of patients with Alzheimer's disease. CNS Drug Rev. 2002;8(2):159-176.

12. Houghton PJ, Ren Y, Howes MJ. Acetylcholinesterase inhibitors from plants and fungi. Nat Prod Rep. 2006;23(2):181-199.

13. Houghton PJ, Howes MJ. Natural products and derivatives affecting neurotransmission relevant to Alzheimer's and Parkinson's disease. Neurosignals. 2005;14(1-2):6-22.

14. Birks J, Grimley Evans J, Iakovidou V, Tsolaki M. Rivastigmine for Alzheimer's disease. Cochrane Database Syst Rev. 2009;2: CD001191.

15. Pettenati C, Annicchiarico R, Caltagirone C. Clinical pharmacology of anti-Alzheimer drugs. Fundam Clin Pharmacol. 2003;17(6): 659-672.

16. Mukherjee PK, Kumar V, Mal M, Houghton PJ. Acetylcholinesterase inhibitors from plants. Phytomedicine. 2007;14(4):289-300.

17. Loizzo MR, Tundis R, Menichini F, Menichini F. Natural products and their derivatives as cholinesterase inhibitors in the treatment of neurodegenerative disorders: An update. Curr Med Chem. 2008;15(12):1209-1228.

18. Cavalli A, Bolognesi ML, Mìnarini A, et al. Multi-target-directed ligands to combat neurodegenerative diseases. J Med Chem. 2008;51(3): 347-372.

19. Muñoz FJ, Aldunate R, Inestrosa NC. Peripheral binding site is involved in the neurotrophic activity of acetylcholinesterase. Neuroreport. 1999;10(17):3621-3625.

20. Rampa A, Belluti F, Gobbi S, Bisi A. Hybrid-based multi-target ligands for the treatment of Alzheimer's disease. Curr Top Med Chem. 2011;11(22):2716-2730.

21. Harborne JB, Baxter H, Moss GP. Phytochemical Dictionary. London, UK: Taylor and Francis; 1999.
22. Mehta M, Adem A, Sabbagh M. New acetylcholinesterase inhibitors for Alzheimer's disease. Int J Alzheimers Dis. 2012;2012:728983.

23. Orhan G, Orhan I, Öztekin-Subutay N, Ak F, Şener B. Contemporary anticholinesterase pharmaceuticals of natural origin and their synthetic analogues for the treatment of Alzheimer's disease. Recent Pat CNS Drug Discov. 2009;4(1):43-51.

24. Musiał A, Bajda M, Malawska B. Recent developments in cholinesterases inhibitors for Alzheimer's disease treatment. Curr Med Chem. 2007;14(25):2654-2679.

25. Butler MS. Natural products to drugs: Natural product-derived compounds in clinical trials. Nat Prod Rep. 2008;25(3):475-516.

26. Seidl C, Correia BL, Stinghen AEM, Santos CAM. Acetylcholinesterase inhibitory activity of uleine from Himatanthus lancifolius. Z Naturforsch Sect C J Biosci. 2010;65C(7-8):440-444.

27. Büchi G, Warnhoff EW. The structure of uleine. J Am Chem Soc. 1959;81(16):4433-4434.

28. Borris RP, Lankin DC, Cordell GA. Studies on the uleine alkaloids. II. Some chemical transformations of uleine. J Nat Prod. 1983;46(2): 206-210.

29. Borris RP, Lankin DC, Cordell GA. Studies on the uleine alkaloids I. carbon-13 nmr studies on uleine, 20-epiuleine and (4S)-uleine- $\mathrm{N}_{\mathrm{b}}$-oxide. J Nat Prod. 1983;46(2):200-205.

30. Borris RP, Cordell GA. Studies on the uleine alkaloids. III. Some microbial transformations of uleine. J Nat Prod. 1983;46(2):211-217.

31. Nardin JM, De Souza WM, Lopes JF, Florão Â, Santos CADM, Weffort-Santos AM. Effects of Himatanthus lancifolius on human leukocyte chemotaxis and their adhesion to integrins. Planta Med. 2008;74(10):1253-1258.

32. Barnes CA, Meltzer J, Houston F, Orr G, McGann K, Wenk GL. Chronic treatment of old rats with donepezil or galantamine: Effects on memory, hippocampal plasticity and nicotinic receptors. Neuroscience. 2000;99(1):17-23.

33. Ji HF, Shen L. Berberine: A potential multipotent natural product to combat Alzheimer's disease. Molecules. 2011;16:6732-6740.

34. Huang L, Luo Z, He F, Lu J, Li X. Synthesis and biological evaluation of a new series of berberine derivatives as dual inhibitors of acetylcholinesterase and butyrylcholinesterase. Bioorg Med Chem. 2010;18(12):4475-4484.

35. Hung TM, Na M, Dat NT, et al. Cholinesterase inhibitory and anti-amnesic activity of alkaloids from Corydalis turtschaninovii. J Ethnopharmacol. 2008;119(1):74-80.

36. Hung TM, Ngoc TM, Youn UJ, et al. Anti-amnestic activity of pseudocoptisine from corydalis tuber. Biol Pharm Bull. 2008;31(1):159-162.

37. Jung HA, Min BS, Yokozawa T, Lee JH, Kim YS, Choi JS. AntiAlzheimer and antioxidant activities of Coptidis Rhizoma alkaloids. Biol Pharm Bull. 2009;32(8):1433-1438.

38. Ingkaninan K, Phengpa P, Yuenyongsawad S, Khorana N. Acetylcholinesterase inhibitors from Stephania venosa tuber. J Pharm Pharmacol. 2006;58(5):695-700.

39. Choo CY, Hirasawa Y, Karimata C, et al. Carinatumins A-C, new alkaloids from Lycopodium carinatum inhibiting acetylcholinesterase. Bioorg Med Chem. 2007;15(4):1703-1707.

40. Hirasawa Y, Kato E, Kobayashi J, et al. Lycoparins A-C, new alkaloids from Lycopodium casuarinoides inhibiting acetylcholinesterase. Bioorg Med Chem. 2008;16(11):6167-6171.

41. Halldorsdottir ES, Jaroszewski JW, Olafsdottir ES. Acetylcholinesterase inhibitory activity of lycopodane-type alkaloids from the Icelandic Lycopodium annotinum ssp. alpestre. Phytochemistry. 2010;71(2-3): $149-157$.

42. Tang XC. Huperzine A (shuangyiping): a promising drug for Alzheimer's disease. Acta Pharmacol Sin. 1996;17(6):481-484.

43. Tang XC, Han YF. Pharmacological profile of Huperzine A, a novel acetylcholinesterase inhibitor from Chinese herb. CNS Drug Rev. 1999;5(3):281-300.

44. Tang XC, He XC, Bai DL. Huperzine A: a novel acetylcholinesterase inhibitor. Drugs Future. 1999;24(6):647-663. 
45. Harel M, Schalk I, Ehret-Sabatier L, et al. Quaternary ligand binding to aromatic residues in the active-site gorge of acetylcholinesterase. Proc Natl Acad Sci U S A. 1993;90(19):9031-9035.

46. Saxena A, Qian N, Kovach IM, et al. Identification of amino acid residues involved in the binding of Huperzine A to cholinesterases. Protein Sci. 1994;3(10):1770-1778.

47. Zhang HY. New insights into Huperzine A for the treatment of Alzheimer's disease. Acta Pharmacol Sin. 2012;33(3):1170-1175.

48. Zhang HY, Yan H, Tang XC. Non-cholinergic effects of Huperzine A: beyond inhibition of acetylcholinesterase. Cell Mol Neurobiol. 2008;28(2):173-183.

49. Devkota KP, Lenta BN, Fokou PA, Sewald N. Terpenoid alkaloids of the Buxaceae family with potential biological importance. Nat Prod Rep. 2008;25(3):612-630.

50. Babar ZU, Ata A, Meshkatalsadat MH. New bioactive steroidal alkaloids from Buxus hyrcana. Steroids. 2006;71(13-14):1045-1051.

51. Atta-Ur-Rahman, Feroz F, Naeem I, et al. New pregnane-type steroidal alkaloids from Sarcococca saligna and their cholinesterase inhibitory activity. Steroids. 2004;69(11-12):735-741.
52. Tundis R, Menichini F, Conforti F, et al. A potential role of alkaloid extracts from Salsola species (Chenopodiaceae) in the treatment of Alzheimer's disease. J Enzyme Inhib Med Chem. 2009;24(3): 818-824.

53. Tumiatti V, Bolognesi ML, Minarini A, et al. Progress in acetylcholinesterase inhibitors for Alzheimer's disease: An update. Expert Opin Ther Pat. 2008;18(4):387-401.

54. Corey-Bloom J, Anand R, Veach J. A randomized trial evaluating the efficacy and safety of ENA 713 (rivastigmine tartrate), a new acetylcholinesterase inhibitor, in patients with mild to moderately severe Alzheimer's disease. Int J Geriatr Psychopharmacol. 1998;1(2):55-65.

55. Cavalli A, Bolognesi ML, Mìnarini A, et al. Multi-target-directed ligands to combat neurodegenerative diseases. JMed Chem. 2008;51(3): 347-372.

56. Viegas C Jr, da Silva Bolzani V, Barreiro EJ, Manssour Fraga CA. New anti-Alzheimer drugs from biodiversity: the role of the natural acetylcholinesterase inhibitors. Mini-Rev Med Chem. 2005;5(10): 915-926.

\section{Publish your work in this journal}

Botanics: Targets and Therapy is an international, peer-reviewed, open access journal focusing on the discovery and development of active compounds based upon or found naturally occurring in the plant kingdom that may have therapeutic potential in any disease state. The manuscript management system is completely online and includes a very

\section{Dovepress}

quick and fair peer-review system. Visit http://www.dovepress.com/ testimonials.php to read real quotes from published authors. 